\title{
Editorial
}

\section{Ensino de Medicina Geral e Familiar no Curso de Mestrado Integrado em Medicina da Universidade da Beira Interior.}

\author{
José Augusto Simões \\ Professor Associado Convidado \\ Universidade da Beira Interior, Faculdade de Ciências da Saúde \\ http://orcid.org/0000-0003-2264-7086 \\ jars@fcsaude.ubi.pt \\ Filipe Prazeres \\ Professor Auxiliar Convidado \\ Universidade da Beira Interior, Faculdade de Ciências da Saúde \\ http://orcid.org/0000-0002-2849-5194 \\ filipeprazeresmd@gmail.com \\ Luiz Miguel Santiago \\ Professor Associado com Agregação \\ Universidade de Coimbra, Faculdade de Medicina \\ Ex-Regente de CSP da FCS-UBI \\ http://orcid.org/0000-0002-9343-2827 \\ Imsantiago@netcabo.pt \\ Miguel Castelo-Branco \\ Professor Associado com Agregação \\ Universidade da Beira Interior, Faculdade de Ciências da Saúde \\ Presidente da Faculdade de Ciências da Saúde e Diretor do Curso de Mestrado \\ Integrado em Medicina \\ https://orcid.org/0000-0002-6191-5912 \\ mcbranco@fcsaude.ubi.pt
}

A educação médica é um processo organizado que leva à aquisição de conhecimentos, atitudes e aptidões para atingir a proficiência. É um processo contínuo e dinâmico em que o atingir de cada objetivo abre a perspetiva de novos objetivos, permitindo estruturar estratégias mais eficientes para a execução de tarefas. No ensino médico, este processo estrutura-se através de um ciclo pré-clínico de estudos em ciências básicas, seguido de um ciclo clínico de formação médica. No fim, o processo de graduação é concluído e a Universidade reconhece a competência para a prática da medicina ${ }^{1}$.

O ensino de Medicina Geral e Familiar (MGF) na Faculdade de Ciências da Saúde da Universidade da Beira Interior remonta ao início do curso de Medicina nesta Universidade em $2001^{2}$. 
A MGF está incluída na área científica de Saúde Comunitária, no âmbito dos Cuidados de Saúde Primários (CSP), que foram distribuídos por três unidades curriculares (UC): no segundo (CSP I), quarto (CSP II) e quinto (CSP III) anos com 10 ECTS cada uma ${ }^{3}$. Existem ainda três outros momentos de contacto com os CSP. No primeiro ano o estágio observacional em Centro de Saúde de uma semana. No terceiro ano, a iniciar no próximo ano letivo, um estágio pré-clínico de MGF de uma semana e no sexto ano o estágio profissionalizante de quatro semanas em MGF (CSP IV).

Os objetivos pedagógicos de CSP / MGF pretendem que os alunos adquiram o conhecimento, as aptidões e as atitudes necessárias para lidar com as questões de saúde predominantes no âmbito da prática clínica de MGF e do contexto de uma prática centrada no paciente.

Todos os tutores das diferentes UC de CSP são Médicos de Família com a especialidade de MGF e com vínculo laboral à Universidade da Beira Interior, no quadro de acumulação parcial de funções públicas.

A lecionação de MGF, com a exceção do segundo ano, procura decorrer no cenário clínico de unidades funcionais de cuidados de saúde primários e de uma prática médica de acordo com a definição europeia de Medicina Geral e Familiar da WONCA ${ }^{4,5}$ (figura 1).

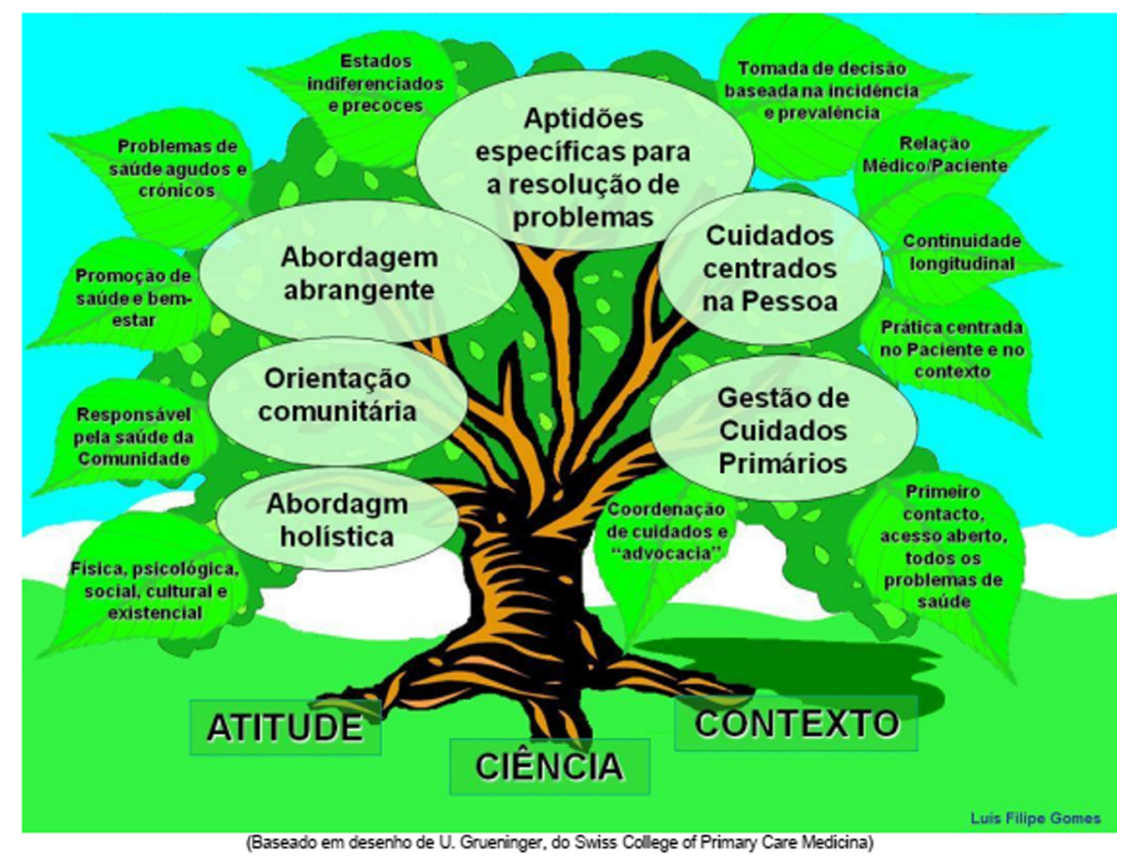

Figura 1. Definição europeia de Medicina Familiar. WONCA 
0 ensino pré-clínico é feito em pequenos grupos de tutoria e os estágios clínicos procuram a relação de 1-2 alunos por tutor. Todos os momentos formativos são sujeitos a avaliação. Pretende-se assim, ensinar Medicina Geral e Familiar (MGF) seguindo os melhores princípios, em termos de dinâmica, interatividade, prática, contexto e ciência.

São objetivos das três Unidades Curriculares (UC) de Cuidados de Saúde Primários (CSP):

- CSP I - O básico dos Cuidados de Saúde Primários e o contexto familiar - ( $2^{\circ}$ ano):

- Caracterizar a equipa de CSP;

- Entender como as unidades funcionais de CSP prosseguem a sua visão geral e familiar;

- Entender como os CSP se organizam e relacionam com a medicina hospitalar e com outros contextos de prática da Medicina;

- Conhecer a importância da promoção e desenvolvimento dos Programas Nacionais de Saúde;

- Conhecer a importância da família dos pacientes na relação saúde/ doença.

- $\operatorname{CSP} \|$ ( $4^{\circ}$ ano):

- Promover que os alunos adquiram o conhecimento, as aptidões e as atitudes necessárias para enfrentar os problemas de saúde mais prevalentes no âmbito da MGF e do seu contexto de prática clínica;

- Promover que os alunos contactem com os conceitos de Medicina Centrada na Pessoa, Empatia Médica e Capacitação da Pessoa.

- Promover que os alunos adquiram boas aptidões de comunicação;

- Promover que os alunos façam anotações e registos clínicos adequados;

- Promover que os alunos realizem uma consulta centrada na pessoa e de acordo com o modelo SOAP ${ }^{7,8}$.

- $\operatorname{CSP}$ III (5 ano):

- Adquirir conhecimentos, aptidões e atitudes necessárias para abranger os problemas de saúde mais comuns na prática da MGF;

- Adquirir conhecimentos, aptidões e atitudes éticas, de medicina centrada na pessoa, empatia e capacitação da pessoa;

- Adquirir conhecimentos e competências para atuar nos diferentes níveis de Prevenção em Medicina;

- Adquirir conhecimentos e competências para classificar de acordo com a ICPC-2;

- Adquirir conhecimentos, aptidões e atitudes necessárias para a gestão da Multimorbidade e da Polifarmacoterapia. 
- CSP IV - que não sendo unidade curricular autónoma (porque na logica de residências de "Prática Clínica" não existem, mas funciona como bloco autónomo - (6 ano):

- Adquirir conhecimentos, aptidões e atitudes necessárias para a realização e gestão de uma consulta.

- Desenvolver competências clínicas sendo capaz de identificar as necessidades de cuidados do doente, da família e da comunidade e planear e gerir as atividades e intervenções daí decorrentes e de monitorizar a sua evolução.

- Desenvolver a capacidade de trabalhar em cooperação com os outros profissionais que integram as equipes de saúde.

- Consolidar o reconhecimento do papel do médico de família como nuclear dentro do serviço nacional de saúde e aperfeiçoar o processo de centralidade na pessoa.

Com as diferentes UC de CSP pretende-se que os alunos terminem o curso de Medicina com conhecimentos e competências para:

- Abordagem interessada e holística das pessoas que recorrem aos serviços de saúde.

- Compreensão da dimensão do papel do médico de família e da abordagem necessária à resolução dos problemas relacionados com a medicina familiar, o que inclui:

- Capacidade em lidar com a ambiguidade;

- Utilização de dados estatísticos na tomada de decisões;

- Utilização da intuição na tomada de decisões;

- Recolha e registo de dados e informação;

- Compreensão dos marcadores e fatores de risco;

- Compreensão da função da família e problemas associados;

- Gestão do tempo no diagnóstico e tratamento da doença;

- Compreender a abordagem centrada na pessoa.

- Compreensão de:

- Morbilidade da comunidade;

- Apresentação de problemas;

- Padrões de sintomas e queixas;

- Medicamentos e tratamentos frequentemente utilizados;

- Multimorbilidade e polifarmacoterapia;

- Adequar ao contexto dos Cuidados de Saúde Primários Portugueses;

- Importância do trabalho em equipa e da aprendizagem contínua ao longo da vida;

- Abordagem crítica como método de crescimento profissional e melhoria na qualidade de prestação de serviços. 


\section{Como se operacionaliza este programa?}

CSP I: 100 horas de tutoria (36 horas) e estudo orientado: Fundamentos básicos, observação e perceção do que foi ensinado na tutoria;

CSP II: 112 horas de tutoria e prática com tutor em gabinete médico (64 horas): método WEED - SOAP aprendido, aplicado e avaliado (por tutor e consulente $)^{7,8}$;

CSP III: 120 horas de tutoria e prática com tutor em gabinete médico (64 horas): desenvolvimento de consulta e observação do ambiente dos Cuidados de Saúde Primários;

CSP IV: 100 horas de prática com tutor em gabinete médico: desenvolvimento de consulta e de prática clínica diária.

\section{Como se faz a avaliação dos alunos?}

CSP I: teste de escolha múltipla no fim de cada unidade pedagógica, três no total, e um teste integrado de todo o conteúdo da UC e uma estação OSCE, na avaliação básica integrada no final do ano letivo. Avaliação qualitativa de comportamentos e atitudes no decorrer da UC. Os alunos que não atingem os objetivos propostos são avaliados em exame final de todo o conteúdo de CSP I;

CSP II: teste de escolha múltipla no fim da rotação, realização de uma consulta segundo a metodologia SOAP (com avaliação pelo tutor através de lista de verificação, e pelo consulente), avaliação de trabalho observacional sobre tema proposto no início do ano letivo e realização de duas estações OSCE, na avaliação clínica integrada no final do ano letivo. Avaliação qualitativa de comportamentos e atitudes no decorrer da UC. Os alunos que não atingem os objetivos propostos são avaliados em exame final de todo o conteúdo de CSP II;

CSP III: teste de escolha múltipla no fim da rotação, realização de uma consulta (com avaliação pelo tutor através de lista de verificação, e pelo consulente), avaliação de trabalho observacional sobre tema proposto no início do ano letivo e realização de duas estações OSCE, na avaliação clínica integrada no final do ano letivo. Avaliação qualitativa de comportamentos e atitudes no decorrer da UC. Os alunos que não atingem os objetivos propostos são avaliados em exame final de todo o conteúdo de CSP III.

CSP IV: Avaliação qualitativa de comportamentos e atitudes no decorrer do estágio. 


\section{Referências Bibliográficas}

1. Santos $P$, Alves L, Simões JA. What distinguishes a competent doctor in medical education? Int J Med Educ. 2017; 8:270-272. Doi: 10.5116/ijme.595f.b2ad.

2. Universidade da Beira Interior. UBI em números 2003/2008; pág.6. Disponível em https://www.ubi.pt/Ficheiros/PDF/Conteudos/ubi_em_numeros_03_08.pdf.

3. Universidade da Beira Interior. Plano de Estudos Medicina. 2018. Disponível em https://www.ubi.pt/PlanoDeEstudos/52/1595/2018.

4. WONCA Europa. A definição europeia de Medicina Geral e Familiar (Clínica Geral/ Medicina Familiar). 2002. Disponível em http://www.woncaeurope.org/sites/default/files/documents/European\%20Definition\%20in\%20Portuguese.pdf.

5. European Academy of Teachers in General Practice. A definição europeia de Medicina Geral e Familiar (Clínica Geral/Medicina Familiar). Versão Reduzida. EURACT 2005. Rev Port Clin Geral. 2005; 21:511-6.

6. European Academy of Teachers in General Practice. A definição europeia de Medicina Geral e Familiar (Clínica Geral/Medicina Familiar). Versão Reduzida. EURACT 2005. Disponível em http://www.apmgf.pt/ficheiros/Definicao_MGFEURACT_2005.pdf.

7. Santiago LM, Neto I. SOAP Methodology in General Practice/Family Medicine Teaching in Practical Context. Acta Med Port. 2016 Dec; 29(12):854-859. Doi: 10.20344/amp.8405.

8. Santiago LM, Queirós V, Neto I, Castelo-Branco M, Barata LT. Lista de Verificação em Consulta para Estudantes de CSPII | 4 Ano no Ano Letivo 2012/2013 na Faculdade de Ciências da Saúde da Universidade da Beira Interior. Rev ADSO. 2013; 2: 23-28. 